\title{
Investigation of hydrolyzed ceramide in Thai color rice (Oryza sativa L.) and by- products
}

\author{
Paosila, C., Rumpagaporn, P. and *Na Jom, K. \\ Department of Food Science and Technology, Faculty of Agro-Industry, Kasetsart University, 50 Ngam \\ Wong Wan Road, Lad Yao, Chatuchak, Bangkok 10900, Thailand
}

\author{
Article history: \\ Received: 25 May 2020 \\ Received in revised form: 25 \\ September 2020 \\ Accepted: 30 November 2020 \\ Available Online: 6 \\ December 2020
}

\section{Keywords:}

Ceramide,

Hydrolyzed ceramide,

GC-FID,

Color rice,

Rice by-products,

PCA

DOI:

https://doi.org/10.26656/fr.2017.4(S4).009

\begin{abstract}
Ceramide is a sphingolipid, which provides health benefits. Gas chromatography coupled with flame ionized detector (GC-FID) was developed for targeted analysis of hydrolyzed ceramide in color rice and by-products. Method validation was done by means of linearity, repeatability and \% recovery. $R^{2}$ of 0.99 by means of linearity equation of the method was obtained. The recovery was in the range of $69.85-108.73 \%$ with RSD of normalized peak area lower than $10 \%$. Hydrolyzed ceramide was found in unpolished rice, both glutinous and non-glutinous rice and its by-products including, defatted rice bran, rice bran wax and rice bran oil. The relationship between varieties of rice color and ceramide content was classified using principal component analysis (PCA) into 2 groups, including dark and pale color rice group. The highest levels of hydrolyzed ceramide as $21.11 \pm 0.02$ $\mathrm{mg} / 100 \mathrm{~g}$ was found in Mali Nil Surin (MNS), black non-glutinous rice. Whereas white non-glutinous rice named Seebukantang (SBK) contained the lowest content of hydrolyzed ceramide as $12.69 \pm 0.03 \mathrm{mg} / 100 \mathrm{~g}$. The amount of ceramide in by-products found in defatted rice bran, rice bran oil and rice bran wax were 17.43 $\pm 0.38,14.67 \pm 0.16$ and $12.54 \pm 0.41 \mathrm{mg} / 100 \mathrm{~g}$, respectively.
\end{abstract}

\section{Introduction}

Ceramide is a lipid compound in plant and animal cell membranes. The chemical structure is made up of C18 aliphatic amide or sphingoid, in which 1-2 hydroxyl groups at the position of $\mathrm{C} 3$ and $\mathrm{C} 4$ together with double bonds at positions of $\mathrm{C} 4$ and $\mathrm{C} 8$, i.e. 4-sphingenine (d18:1), 4,8-sphingadienine (d18:2) and 4-hydroxy-8sphingenine (t18:1) linked with a fatty acid (C16-C26) at amide position (Figure 1) (Mano et al., 1999; Shimoda, 2009; Nilsson, 2012; Ishikawa et al., 2016). Ceramide is associated with various mechanisms of the human body such as cell proliferation and apoptosis (Vesper et al., 1999; Schmelz et al., 2000). It involves in the moisture barrier functional protection in the epidermis (Grove and Kligman, 1983) and inhibition of melanin synthesis (Kim et al., 2002). Ceramide has been found in plant-based foods especially rice, which is an economical crop widely cultivated in Thailand. Not only rice is eaten as a daily staple food, but also rice products and by-products have been processed in Thailand. Based on rice processing, rough rice is initially milled to remove husk layer and polished to remove rice bran from endosperm to obtain polished rice. Rice bran has become an important by-product of rice. Rice bran contains vitamins, minerals, essential fatty acids, dietary fiber, phytosterol and ceramide (Gul et al., 2015). The content of ceramide in rice bran was found to be higher than rice endosperm (Fujino et al., 1985). Therefore, rice bran could probably be a major source of ceramide. Rice bran has been generally processed by using a cold-press method to obtain crude oil before precipitating at low temperature or winterization process to precipitate rice bran wax, which contains fatty acid, fatty alcohol and ester (Vali et al., 2005; Kim, 2008). The non-precipitated fraction is dewaxed rice bran oil. The major compositions of rice bran oil are palmitic acid (C16:0), oleic acid (C18:1), linoleic acid (C18:2) (Rukmini, 1998) and bioactive compounds, including tocopherols, phytosterols, $\gamma$-oryzanol and policosanol (Wongwaiwech, 2018). Not only the wax but also defatted rice bran is another waste from the production of rice bran oil. To investigate the content of ceramide in rice and those by-products, a step of acid hydrolysis has been recommended to improve ceramide purity and applied in gas chromatography or high-performance liquid chromatography. Strong acid solutions are able to isolate total ceramide or hydrolyzed ceramide from complex lipids and fatty acids and also to remove sugar residue in glucosylceramide, which is mainly the natural 
ceramide structure in rice (Goto et al., 2012; Yamaguchi and Orgawa, 2012). So far, GC-based method with suitable capillary column and detector has been applied to investigate lipophilic compounds. It is highly sensitive and universal. The methodology applied for the analysis of ceramide has to offer the possibility to detect, resolve, identify and quantify spectrum of ceramide in a wide range of concentration. The objectives of this study were to establish a GC-FID method for analysis of hydrolyzed ceramide in 20 varieties of Thai color rice and 3 types of by-products including, defatted rice bran, rice bran wax and dewaxed rice bran oil.

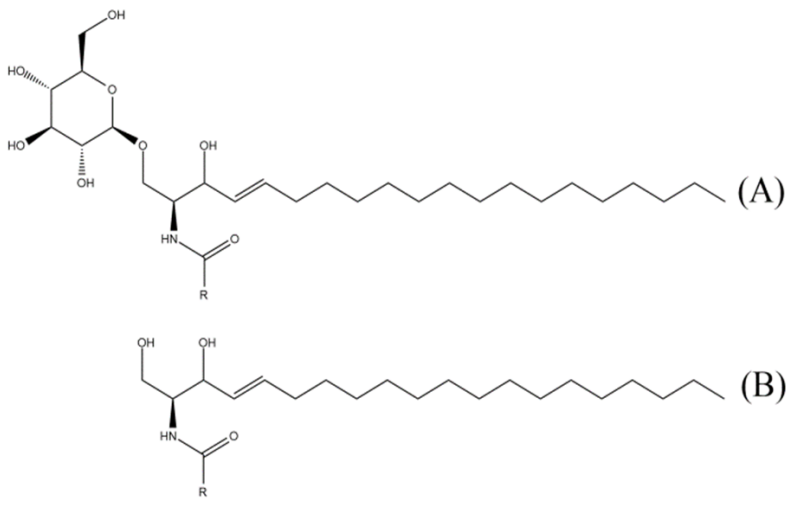

Figure 1. Glucosylceramide (A) and Ceramide (B).

\section{Materials and methods}

\subsection{Sample materials}

A total of twenty varieties of color rice (Table 1) during the 2016 growing season and harvested in 2017 were provided by the Department of Rice, The Ministry of Agriculture and Co-operatives, Bangkok, Thailand. Defatted rice bran (D), rice bran wax (W) and rice bran oil (O) (Table 1) were by-products of Khao Dawk Mali 105 obtained in 2017 provided by Medifood Co., Ltd., Bangkok, Thailand.

\subsection{Sample preparation}

Paddy rice samples were dehusked using a NW 1000 Turbo laboratory dehusker (Thongtrawee, Thailand). Dehulled rice grains (8-12\% moisture content) were finely ground (100 mesh) by using a hammer mill (Retsch GmbH, Haan, Germany) to obtain color rice powder approximately $10 \pm 0.5$ g. The flour was immediately freeze-dried for a total of $48 \mathrm{hr}$ using a Heto FD 2.5 conventional freeze-drying machine (HetoHolten A/S, Allerrød, Denmark) with the final moisture content of $\leq 2 \%$. The freeze-dried flour was stored at $20^{\circ} \mathrm{C}$ in a tightly sealed aluminum bag.

Defatted rice bran with $\leq 2 \%$ moisture content was finely ground (100 mesh). The powder of defatted rice bran and rice bran wax was kept in tightly closed LDPE bag. Whereas, refined rice bran oil was kept in tightly closed LDPE bottles. All samples were stored at $-20^{\circ} \mathrm{C}$ until analysis.

Table 1. Description of 20 varieties of Thai color rice grains and 3 by-products of KMDL 105 rice

\begin{tabular}{clc}
\hline Name & \multicolumn{1}{c}{ Description } & Color/Type \\
\hline MDNK & Mali Dam Nong Khai (RD83) & BNG \\
MNS & Mali Nil Surin & BNG \\
RB & Riceberry & BNG \\
HKN & Hom Kradang Ngah 59 & RNG \\
TCP & Tubtim Chumphae (RD69) & RNG \\
SY & Sangyod Phatthalung & RNG \\
JC & Jek Chuey 1 & WNG \\
KMR & Khai Mod Rin 3 & WNG \\
KTH & Khao Tah Haeng 17 & WNG \\
LP & Leuang Pratew 123 & WNG \\
PT1 & Pathum Thani 1 & WNG \\
PT80 & Pathum Thani 80 (RD31) & WNG \\
SBK & Seebukantang & WNG \\
KCM & Kum Chiang Mai & BG \\
KCMTK & Kum Chiang Mai (Ton-Kew) & BG \\
NDM & Niaw Dam Mor 37 & BG \\
KN & Kum Nan & BG \\
KNP & Kum Nai Prom & BG \\
KLP & Kum Leum Pua & BG \\
SMJ & Sew Mae Jan & WG \\
Defat & Defatted rice bran & D \\
Oil & Dewaxing rice bran oil & O \\
Wax & Rice bran wax & W \\
\hline B
\end{tabular}

Black non-glutinous rice (BNG), Red non-glutinous rice (RNG), Colorless non-glutinous rice (WNG), Black glutinous rice (BG), Colorless glutinous rice (WG), Defatted rice bran (D), Rice bran oil (O) and Rice bran wax (W)

\subsection{Lipid extraction}

The extraction method was modified from Goto et al. (2012). $1 \mathrm{~g}$ of sample (w/w) and $0.1 \mathrm{mg}$ of N-lauroylD-sphingosine as internal standard (Sigma-Aldrich Company, St. Louis, MO, USA) was extracted by $10 \mathrm{ml}$ of chloroform: methanol (2:1) using a sonicator (575TAE, Advance Ceramics Technology (M) Sdn. Bhd., Pulau Pinang, Malaysia) at $60 \mathrm{~Hz}, 748 \mathrm{~W}$ for 30 mins. The solution was then centrifuged (Biofuge stratos, Thermo Electron LED GmbH, Germany) at $3000 \mathrm{rpm}$ for 10 mins. The extracted supernatant was mixed in 6.4 $\mathrm{ml}$ of $0.88 \% \mathrm{KCl}$ to separate the lipid fraction from the non-lipid fraction. The lipid fraction in chloroform was evaporated using a parallel evaporator (Syncore V-700, BÜCHI Labortechnik AG, Switzerland) at $60^{\circ} \mathrm{C}$ under vacuum until dry.

\subsection{Acid hydrolysis and fractionation}

The dried lipid fraction was hydrolyzed following 
the method described by Goto et al. (2012) with slight modification. An aliquot $(1 \mathrm{~mL})$ of $1 \mathrm{M}$ aqueous hydrochloric acid in methanol was added into the dried extract and incubated at $70^{\circ} \mathrm{C}$ for $18 \mathrm{hrs}$ in a shaking water bath (BS-11, Oskon Co., Ltd., Thailand) to hydrolyzed the complex lipid. The fatty acid methyl ester was washed 4 times by $2 \mathrm{~mL}$ of hexane and adjusted with $10 \mathrm{M}$ sodium hydroxide to obtain the $\mathrm{pH}$ between $10-12$, followed by adding $1.5 \mathrm{~mL}$ of distilled water to stabilize the hydrolyzed ceramide before extracting twice by adding $2 \mathrm{~mL}$ of diethyl ether. The solution was then washed 1 time by adding $1 \mathrm{~mL}$ of distilled water. After separating the water phase, diethyl ether phase was evaporated with a parallel evaporator at $50^{\circ} \mathrm{C}$ under vacuum until dried.

The hydrolyzed ceramide was re-dissolved in $0.1 \mathrm{~mL}$ of chloroform and loaded onto a $300 \mathrm{mg}$ silica gel column of solid-phase extraction. The minor lipid was extracted with $4 \mathrm{~mL}$ of chloroform and hydrolyzed ceramide was extracted with $4 \mathrm{~mL}$ of chloroform: methanol (1:4) and evaporated using a parallel evaporator at $60^{\circ} \mathrm{C}$ under vacuum until dry.

\subsection{Silylation}

The hydrolyzed ceramide was silylated by $100 \mu \mathrm{L}$ of $\mathrm{N}, \mathrm{O}$ Bis(trimethylsily)-trifluoroacetamide and $100 \mu \mathrm{L}$ of pyridine at $60^{\circ} \mathrm{C}$ for 60 mins before injected into gas chromatography 6890 plus coupled with flame ionized detector (GC-FID).

\subsection{Gas chromatography analysis}

An aliquot $(2 \mu \mathrm{L})$ of the silylated solution was injected 3 times into GC-FID system (Hewlett Packard, Palo Alto, CA, USA) in splitless injection mode, with the HP-5, $30 \mathrm{~m} \times 0.32 \mathrm{~mm}$ i.d., fused silica capillary coated with a $0.25 \mu \mathrm{m}$ film of $5 \%$-diphenyl-95\% dimethylpolysiloxane (Agilent technologies, Santa Clara, CA, USA). Helium at a flow rate of $1 \mathrm{ml} / \mathrm{min}$ was used as a carrier gas at a constant inlet pressure of $165 \mathrm{kPa}$. The oven temperature program was started at $180^{\circ} \mathrm{C}$ and was stable for $5 \mathrm{mins}$, then was increased at $5^{\circ} \mathrm{C} / \mathrm{min}$ to $220^{\circ} \mathrm{C}$ (20 mins hold) and held at $250^{\circ} \mathrm{C}$ (5 mins hold). The injector temperature was $250^{\circ} \mathrm{C}$ and the detector temperature was $250^{\circ} \mathrm{C}$. FID data were acquired by means of commercially available software (HPChemstation A.06.03, Hewlett Packard, Palo Alto, CA, USA). Hydrolyzed ceramide was identified by comparing retention times with the silylated reference compound. Quantification was performed using peak area, which was normalized on the basis of internal standards.

\subsection{Method validation}

Glucosylceramide as an external standard (Nagara Science Company, Ltd., Gifu, Japan), was prepared in chloroform. In order to determine linearity, the external standard in a range of $0.1-0.3 \mathrm{mg} / \mathrm{mL}$ was silylated and investigated by GC-FID as described in 2.4-2.6. Normalized peak area obtained by GC-FID analysis was plotted against the concentration of the external standard. For quantitative evaluation of the linearity, the correlation coefficient between the normalized peak area and the concentration of the standard was calculated. Limit of detection (LOD) and limit of quantification (LOQ) were defined at a signal to noise $(\mathrm{S} / \mathrm{N})$ ratio of $3: 1$ and 10:1, respectively, by 3 aliquots of the extracts subjected to the described protocol and analyzed by GCFID. The recovery was determined by adding $0.1 \mathrm{mg}$ of glucosylceramide into $1 \mathrm{~g}$ of sample with the described extraction protocol. In order to confirm the reproducibility of the method, the hydrolyzed ceramide in spiked and non-spiked color rice and by-products were determined 6 times and calculated\% recovery. Repeatability was determined by triplicate analysis of the sample comprising extraction, hydrolysis, derivatization and GC-FID analysis.

\subsection{Statistical analysis}

Univariate analysis using analysis of variance (ANOVA) with the SPSS statistic software program version 16.0 (SPSS Inc., IBM, New York, USA) was used to analyze the variance of data. Duncan's multiple range test at $p \leq 0.05$ level of significance was used for determining the mean difference of experimental data. Multivariate analysis was used to classify all color rice samples according to the hydrolyzed ceramide content by hierarchical clustering analysis (HCA) and principal component analysis (PCA) with PAST statistical analysis program version 4.0 from University of Oslo, Norway.

\section{Results and discussion}

\subsection{Methods validation}

The GC-FID chromatogram of hydrolyzed ceramide (Figure 2) showed that the peak area in all samples was detected at the retention time of 19.57-19.60 mins. The calibration model was developed in order to evaluate a correlation between the spectral data and the hydrolyzed ceramide content determined by reference analysis. Eventually, the calibration curve must infer a rule for prediction of the reference analysis results in future samples. By this methodology, the standard curve (Figure 3) and linearity equation were obtained. The concentration of the standard substance ranging 1-3 $\mu \mathrm{g} /$ $\mathrm{ml}$ of hydrolyzed ceramide was correlated to spectrum with $\mathrm{R}^{2}$ (linearity; correlation coefficient) of 0.99 . This 
demonstrates that the peak area and the concentration of the standard substance are directly related to $99 \%$, being at an acceptable level (Goto et al., 2012). The LOD and LOQ of the method at 0.77 and $2.57 \mu \mathrm{g} / \mathrm{mL}$, respectively, was clarified. A similar range of LOD and LOQ was also reported by previous ceramide analytical methodology by using HPLC analysis (Zhou et al., 2002).

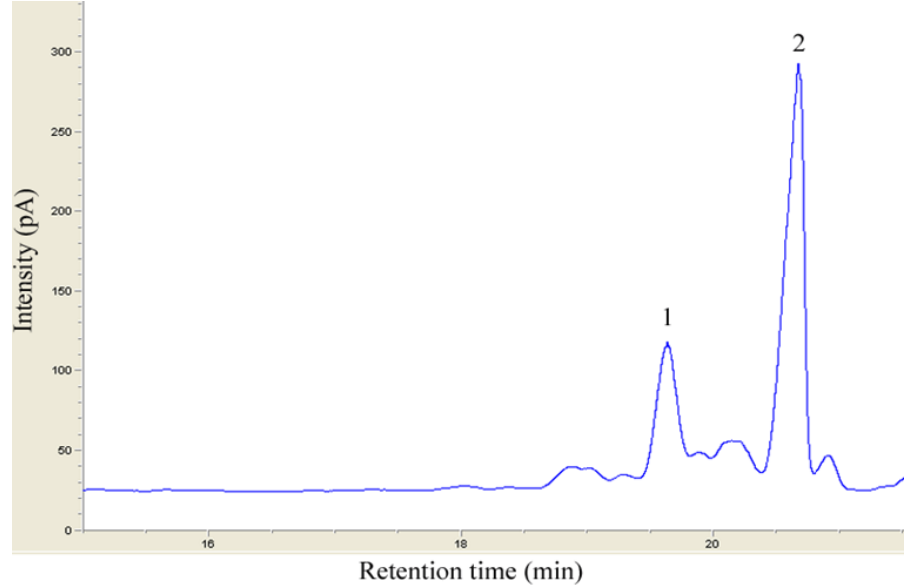

Figure 2. Chromatogram of hydrolyzed ceramide in rice (1) and internal standard (2).

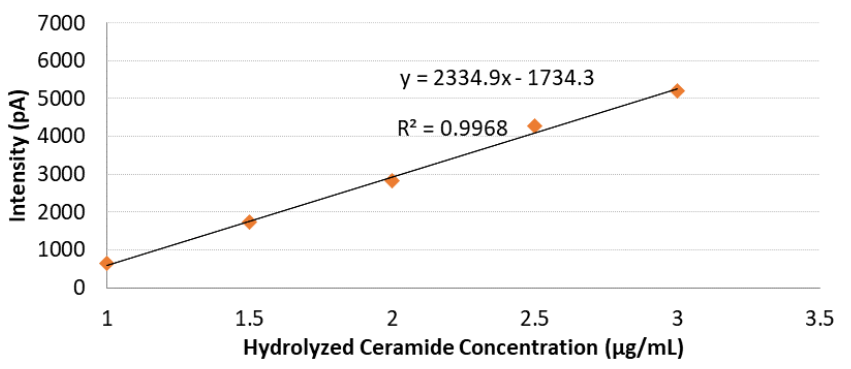

Figure 3. Calibration curves of peak area and hydrolyzed ceramide concentration $(\mu \mathrm{g} / \mathrm{mL})$

A sufficient recovery of hydrolyzed ceramide from color rice and by-product materials is a prerequisite to apply the methodology for the detection of hydrolyzed ceramide in rice samples. The \% recovery extracted and RSD from the color rice and by-products shown in Table 2 were classified according to 8 types of samples, including BNG, RNG, WNG, BG, WG, D, O, and W. The recovery experiment proves that the developed method is able to detect and quantify hydrolyzed ceramide in the samples. In order to determine the percentage of hydrolyzed ceramide recovered from color rice and by-product materials after extraction, hydrolysis and silylation, known amount of external standard was spiked at the beginning of the analytical procedure. Results gained by GC-FID analysis of peak area obtained from the spiked and the non-spiked sample were compared to that gained from standard spiked prior to $\mathrm{GC}$ analysis. \% Recovery determined for $\mathrm{WNG}, \mathrm{BG}$, WG, BNG, RNG, D and $\mathrm{O}$ was over $80 \%$, which was acceptable for rice grain and oil product (Goto et al., 2012, Yamaguchi and Ogawa, 2012). This experiment demonstrates the appropriateness of the applied method to investigate the hydrolyzed ceramide in the rice samples. Only W obtain below $70 \%$ recovery. The low recovery rate in the wax might probably due to major fatty alcohol and wax ester which classified as apolar lipid species. Their polarities may disturb the ceramide quantities during extraction similar to heptadecanoic anhydride standard in wax ester analysis (Iven et al., 2013)

Sufficient repeatability is another condition to be obtained in order to apply the developed methodology to investigate the hydrolyzed ceramide in color rice and byproducts. Data obtained for the detection of external standard and hydrolyzed ceramide in the samples demonstrated the good intralaboratory repeatability of the extraction procedure as well as of the overall protocol involving fractionation, acid hydrolysis, derivatization and GC-FID analysis. As shown in Table 2, relative standard deviation (RSD) of the normalized peak area of hydrolyzed ceramide was lower than $10 \%$. This proves the proper repeatability of the established methodology.

Table 2. \% Recovery of hydrolyzed ceramide in Thai color rice and by-products

\begin{tabular}{ccc}
\hline Color/Type & \% Recovery & \% RSD \\
\hline W & $69.85 \pm 4.82^{\mathrm{f}}$ & 6.91 \\
O & $80.33 \pm 1.97^{\mathrm{e}}$ & 2.45 \\
D & $103.80 \pm 1.50^{\mathrm{ab}}$ & 1.44 \\
RNG & $90.97 \pm 3.18^{\mathrm{d}}$ & 3.50 \\
BNG & $95.44 \pm 2.48^{\mathrm{cd}}$ & 2.60 \\
WG & $98.63 \pm 5.72^{\mathrm{bc}}$ & 5.80 \\
BG & $103.19 \pm 1.54^{\mathrm{ab}}$ & 1.49 \\
WNG & $108.73 \pm 1.69^{\mathrm{a}}$ & 1.55 \\
\hline
\end{tabular}

Values are expressed as means \pm standard deviation of three replicates. Values with different superscripts within the column are significantly different $(p \leq 0.05)$.

\subsection{The content of hydrolyzed ceramide in Thai color} rice

The level of hydrolyzed ceramide found in all color rice samples ranged between $13.95-19.31 \mathrm{mg} / 100 \mathrm{~g}$ $(p \leq 0.05)$ as shown in Table 3 . Differentiate analysis by the means of principal component analysis (PCA) is able to give an overview of the grouping of samples regarding the amount of hydrolyzed ceramide. The graphical presentation of sample grouping by PCA score plot was shown in Figure 4. The plot revealed that along the horizontal axis, the samples could be classified by the relationship between hydrolyzed ceramide concentration and the rice color into 2 groups, including Thai pale and dark color rice. The results, therefore, refined the influence of dark and pale coloration of Thai rice samples on the content of hydrolyzed ceramide. The 


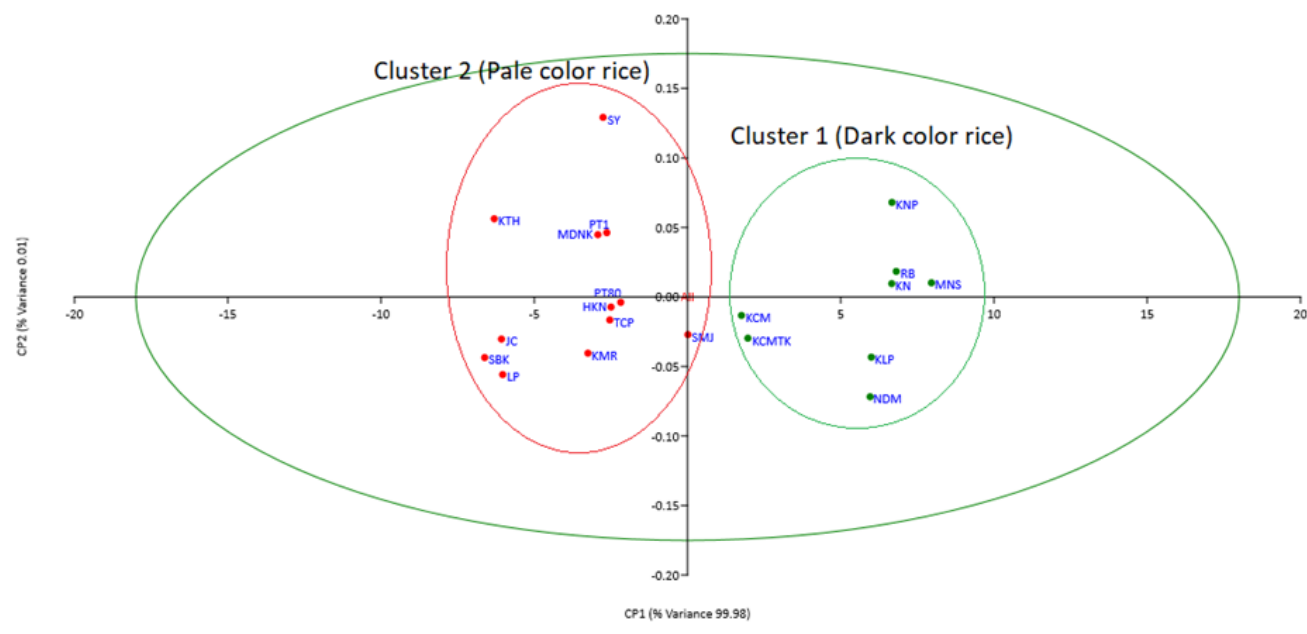

Figure 4. Principal component analysis (PCA) score plot of standardized GC-FID peak area of hydrolyzed ceramide in 20 varieties of Thai color rice varieties.

Table 3. Hydrolyzed ceramide content in 20 varieties of Thai color rice.

\begin{tabular}{ccc}
\hline Name & Color & Hydrolyze ceramide content $(\mathrm{mg} / 100 \mathrm{~g})$ \\
\hline SBK & WNG & $12.69 \pm 0.03^{\mathrm{n}}$ \\
KTH & WNG & $12.87 \pm 0.06^{\mathrm{m}}$ \\
JC & WNG & $13.01 \pm 0.03^{1}$ \\
LP & WNG & $13.03 \pm 0.06^{1}$ \\
KMR & WNG & $14.64 \pm 0.06^{\mathrm{k}}$ \\
MDNK & BNG & $14.83 \pm 0.03^{\mathrm{j}}$ \\
SY & RNG & $14.93 \pm 0.09^{\mathrm{i}}$ \\
PT1 & WNG & $15.00 \pm 0.03^{\mathrm{hi}}$ \\
TCP & RNG & $15.05 \pm 0.02^{\mathrm{h}}$ \\
HKN & RNG & $15.08 \pm 0.01^{\mathrm{h}}$ \\
PT80 & WNG & $15.26 \pm 0.03^{\mathrm{g}}$ \\
SMJ & WG & $16.52 \pm 0.03^{\mathrm{f}}$ \\
KCM & BG & $17.53 \pm 0.03^{\mathrm{e}}$ \\
KCMTK & BG & $17.65 \pm 0.07^{\mathrm{d}}$ \\
NDM & BG & $19.96 \pm 0.09^{\mathrm{c}}$ \\
KLP & BG & $19.98 \pm 0.06^{\mathrm{c}}$ \\
KN & BG & $20.36 \pm 0.01^{\mathrm{b}}$ \\
KNP & BG & $20.37 \pm 0.04^{\mathrm{b}}$ \\
RB & BNG & $20.45 \pm 0.02^{\mathrm{b}}$ \\
MNS & BNG & $21.11 \pm 0.02^{\mathrm{a}}$ \\
\hline
\end{tabular}

Values are expressed as means \pm standard deviation of three replicates. Values with different superscripts within the column are significantly different $(p \leq 0.05)$.

hierarchical clustering analysis (HCA) in similarity mode was employed as shown in Figure 5 in order to confirm the cluster pattern of the samples by PCA. A comparable result was achieved, in which Thai color rice samples were divided into 2 groups by dark and pale color in relationship to the hydrolyzed ceramide content as previously shown in the PC biplot. Thai dark color rice group, including RB, MNS, KNP, KN, KLP, NDM, $\mathrm{KCM}$ and KCMTK were found that the hydrolyzed ceramide concentration ranged from $17.53 \pm 0.03$ to
$21.11 \pm 0.02 \mathrm{mg} / 100 \mathrm{~g}(p \leq 0.05)$. On the other hand, Thai pale color rice group, including SMJ, HKN, TCP, SY, SMJ, PT80, PT1, KMR, LP, KTH, JC, SBK and MDNK, contained hydrolyzed ceramide ranged from $12.69 \pm 0.03$ to $16.52 \pm 0.03 \mathrm{mg} / 100 \mathrm{~g} \quad(p \leq 0.05)$. Ceramide accumulated in the bran layer was higher than the endosperm part (Fujino et al., 1985). Thickness and quantity of rice bran layer influenced the ceramide content in rice. Mali Nil Surin (MNS) and Riceberry (RB) are non-glutinous Thai dark color rice, but the level of hydrolyzed ceramide in MNS has been higher than RB. It might be due to rice bran content in MNS (12.1\% $\mathrm{w} / \mathrm{w})$ was higher than RB $(9.5 \% \mathrm{w} / \mathrm{w})$ (Saiyot et al., 2017). The bran layer of black/purple rice was observed to be thicker or higher in content than red and non-color rice (Paiva et al., 2014). These could be the reason of higher accumulation of ceramide in Thai dark color rice than pale color rice. However, there was only MDNK, which was a Thai black color rice clustered in the same group of Thai pale color rice. Moreover, the PC plot along the vertical axis indicated an impact of variety differentiation of Thai color rice on the level of hydrolyzed ceramide. Tubtim Chumphae (TCP), a Thai red color rice, was observed that it contained hydrolyzed ceramide as $15.05 \pm 0.02 \mathrm{mg} / 100 \mathrm{~g}(p \leq 0.05)$. Whereas a significant lower content of hydrolyzed ceramide as $14.93 \pm 0.09 \mathrm{mg} / 100 \mathrm{~g}(p \leq 0.05)$ was found in another Thai red color rice, Sangyod Phatthalung (SY). Nevertheless, TCP contained $8.5 \%(\mathrm{w} / \mathrm{w})$ of rice bran content, which was lower than SY, as $8.8 \% \mathrm{w} / \mathrm{w}$ (Changsiri et al., 2016). Additionally, Seebukantang (SBK), a Thai non-color rice, was found that it contained a higher amount of rice bran $(11.4 \% \mathrm{w} / \mathrm{w})$ than Thai red color rice and Riceberry (Suwanno et al., 2018), but gave the lowest hydrolyzed ceramide content among all samples in this study. These might be due to several factors affecting on the amount of ceramide in Thai color rice, i.e., genotype, environment and agricultural 
practice. Ceramide content in wheat ranged between 21 $41 \mathrm{mg} / 100 \mathrm{~g}$ was defined as higher than rice, as 2.5-10 $\mathrm{mg} / 100 \mathrm{~g}$ (Sugawara and Miyazawa, 1999; Takakuwa et al., 2005). Soybean ceramide level was quantified in the root $(39 \mathrm{mg} / 100 \mathrm{~g})$ higher than in seed (10.1-35.1 $\mathrm{mg} / 100 \mathrm{~g}$ ) and pericarp $(5 \mathrm{mg} / 100 \mathrm{~g})$ (Gutierrez et al., 2004). Moreover, environment and condition of agricultural practice, e.g. low temperature and oxygen prevailed can trigger the accumulation of ceramide. The low temperature, low oxygen level, oxidative stress resistance or subtropical growing zone, for example, Kirara397 and Yukihiraki (Japanese rice varieties) might synthesize d18:2-ceramide higher than rice cultivated in the tropical zone, e.g. RD19 in Thailand (Mano et al., 1999; Huby et al., 2020).

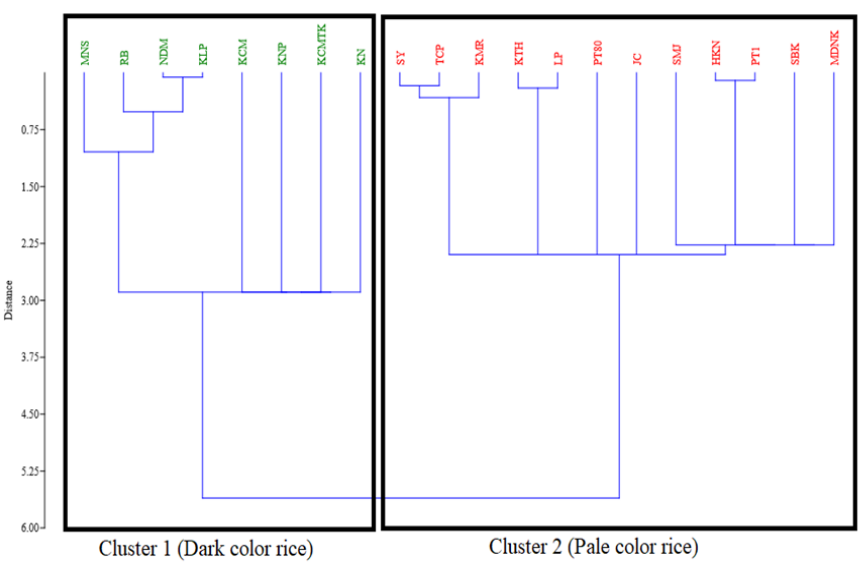

Figure 5. Dendrogram (similarity mode of hierarchical clustering analysis (HCA)) of 20 varieties of Thai color rice based on the content of hydrolyzed ceramide.

\subsection{The amount of hydrolyzed ceramide in by-product materials of KMDL rice}

The hydrolyzed ceramide level in KMDL rice byproducts $(\mathrm{D}, \mathrm{O}$ and $\mathrm{W})$ is shown in Figure 6. The content of hydrolyzed ceramide in sample $\mathrm{D}, \mathrm{O}$ and $\mathrm{W}$ were $17.43 \pm 0.38, \quad 14.67 \pm 0.16$ and $12.54 \pm 0.41 \mathrm{mg} / 100 \mathrm{~g}$ $(p \leq 0.05)$, respectively. Ceramide is a part of plant membrane, especially in the outer layer. Free form of ceramide is naturally combined with other complex lipids for the formation of cerebroside and ganglioside. Bound ceramide in complex chemical structures could be difficult extracted and released from crop seed and grain by any chemical extraction procedure and physical force as polishing and pressing in rice and rice bran oil processing, respectively (Gutierrez et al., 2004). The amount of hydrolyzed ceramide in the defatted rice bran residue (D) was in a similar quantitation as the previous report (Fujino et al., 1985). The total lipid content in rice and product samples was not related to the ceramide level in the samples (Gloria et al., 2018). The result implied that the ceramide content in the refined rice bran oil $(\mathrm{O})$ was lower than that found in the defatted rice bran residue (D) as almost a fold. The major fatty acid constituents in the rice bran oil, including C16:0, C18:1 and $\mathrm{C} 18: 2$, are not involved in the chemical structure of ceramide (Rukmini, 1998). On the other hand, C20-C24 fatty acids as major constituents involved in the ceramide chemical structure were higher level in the rice bran, especially colorless rice (Mano et al., 1999). These might indicate that ceramide remained in the rice bran residue after cold pressing or solvent extraction in oil production. Higher ceramide amount in the crude oil of soybean without refinery was previously reported (Gutierrez and Wang, 2004). Another residue from the process of rice bran oil making is the wax. The ceramide content in the rice bran wax (W) was lower than that found in the defatted rice bran residue (D) and oil $(\mathrm{O})$. Since the rice bran wax was winterized in a step of the oil processing. Complex macromolecule lipids consisting of various fatty alcohols, especially C32-C34 fatty alcohols (Gunawan et al., 2006), were hydrolyzed and form an unexpected complex structure in the precipitated fraction, without ceramide. Therefore, the defatted rice bran residue could be an alternative source for ceramide.

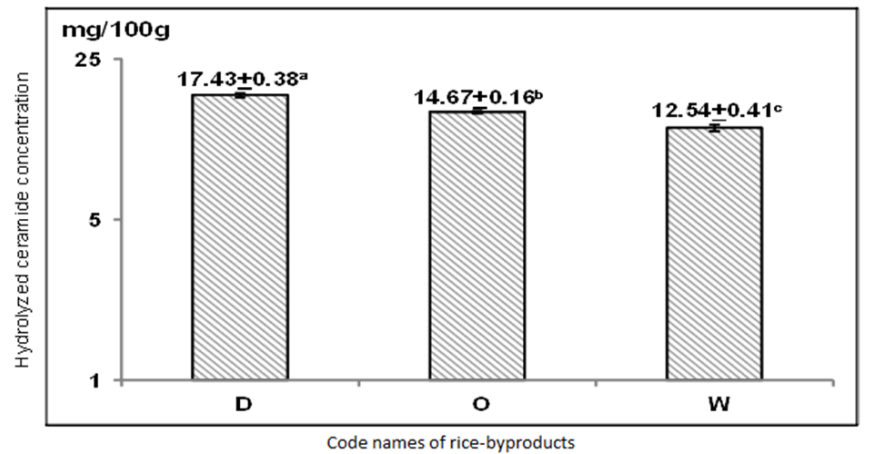

Figure 6. Hydrolized ceramide content in Defatted rice bran residue (D), Rice bran oil (O) and Rice bran wax (W). Values are expressed as means \pm standard deviation of three replicates. Values with different superscripts within the column are significantly different $(p \leq 0.05)$.

\section{Conclusion}

The applied methodology, including solvent extraction, fractionation, acid hydrolysis and GC-FID system, was established for the investigation of hydrolyzed ceramide in Thai color rice and by-products with good linearity, sensitivity, repeatability and reproducibility. The hydrolyzed ceramide content in Thai color rice was under the influence of variety, genetic background, prevailing environment and condition of agricultural practice. Higher hydrolyzed ceramide content was quantified in Thai black and purple rice than that observed in red and colorless rice. Pericarp layer of Thai rice, which is rich in ceramide level could be mostly removed from the rice bran via polishing and refining process in rice and oil processing. A step of cold -pressing and winterization in the process of rice bran oil production could not extract and release ceramide from 
the rice bran to the oil and wax. Most of the ceramide remained in the defatted rice bran residue after the processing of rice bran oil. Therefore, the defatted rice bran could be used as another alternative raw material for ceramide extraction.

\section{Conflict of interest}

The authors declare that there is no conflict of interest regarding the publication of this article.

\section{Acknowledgments}

The authors are grateful to the Department of Food Science and Technology, Faculty of Agro-Industry, Kasetsart University, Bangkok, Thailand for all resources and equipment. Special thanks to Medifood Co., Ltd., Bangkok, Thailand, for budget supports, sample information and discussion.

\section{References}

Changsiri, R., Bureerat, S., Prungkong, T., Pengrueng, A., Pongpanus, A., Rungwattanapong, T., Puntujit, S., Noinopphra, K., Akrawong, P., Kumkaew, D., Noinopphra, P., Kumphookhieo, A., Sunthra, S., Pasopa, S., Srisompan, C., Kumsanpan, P., Leenart, A., Sakulkoo, E., Wongkasem, O., Rukchum, P., Granto, S., Kunolarn, V., Buddhaboon, C., Saleetoe, S., Jumpagate, R., Sripanom, P., Gaewkumjang, C., Tuntaruk, R., Hormsombut, W., Suwannawong, A., Pengrat, J., Mapakhe, J., Songrat, S., Srinark, S., Youngsuk, P., Sudtasarn, G., Jairin, J., Kochasatit, A., Kotchasatit, U., Wongboon, W., Sattayakul, K., Kenlerm, R., Sripodok, S., Nammontri, S., Tiengdeerith, S., Junsena, N., Chaiwut, P., Promnart, P., Chuenban, T., Saiyot, A., Tanaruk, R., Chanaaksorn, P., Dumnil, K., Dumnil, S., Dumnil, S., Khaodee, K., Piyachotisakulchai, N., Suriyaarunroj, D., Letna, S., Kongsuwan, P., Hinting, P., Vorawut, O., Photisiri, W., Dantaweesilpa, W., Ritthipakdee, S., Choosiri, L., Preecha, R., Tumpavisit, S., Cheaupan, K., Wongpiyachon, S., Sukviwat, W., Yaodum, K., Lawanprasert, A., Jiarakongum, S., Taprab, S., Sriratanasak, W., Rattanakarn, W., Dhitikiattipong, R., Combelli, P., Arunmit, S., Chaiwong, J., Intalang, W., Nakornreub, M. and Grasaetep, J. (2016). RD69 (Tubtim Cum Phae), a non-glutinous rice variety. Thai Rice Research journal, 7(2), 30-46.

Fujino, Y., Ohnishi, M. and Ito, S. (1985). Molecular species of ceramide and mono-, di-, tri-, and terraglycosylceramide in bran and endosperm of color rice. Agricutural and Biological Chemistry, 49 (9), 2753-2762.

https:// doi.org/10.1080/00021369.1985.10867139

Gloria, C.A., Overholt, M.F., Dilger, A.C., Boler, D.D. and Stein, H.H. (2018). Effects of full-fat rice bran and defatted rice bran on growth performance and carcass characteristics of growing-finishing pigs. Journal of Animal Science, 96(6), 2293-2309. https:// doi.org/10.1093/jas/sky145

Goto, H., Nishikawa, K., Shionoya, N., Taniguchi, M. and Igarashi, T. (2012). Determination of sphingoid base from hydrolyzed glucosylceramide in rice and wheat by online post-column high-performance liquid chromatography with O-phthalaldehyde derivertization. Journal of Oleo Science, 61(12), 681 -688. https://doi.org/10.5650/jos.61.681

Grove, G.L. and Kligman, A.M. (1983). Age-associated changes in human epidermal cell renewal. The Journal of Gerontology, 38(2), 137-142. https:// doi.org/10.1093/geronj/38.2.137

Gul, K., Yousuf, B., Singh, A.K., Singh, P. and Wani, A.A. (2015). Rice bran: nutritional values and its emerging potential for development of functional food-a review. Bioactive Carbohydrates and Dietary Fibre, 6(1), 24-30. https://doi.org/10.1016/ j.bcdf.2015.06.002

Gunawan, S., Vali, S.R. and Ju, Y. (2006). Purification and identification of rice bran oil fatty acid steryl and wax ester. Journal of American Oil Chemists' Society, 83(5), 449-456. https://doi.org/10.1007/ s11746-006-1225-8

Gutierrez, E. and Wang, T. (2004). Effect of processing on sphingolipid content in soybean products. Journal of American Oil Chemists' Society, 81(10), 971-977. https://doi.org/10.1007/s11746-004-1009-1

Gutierrez, E., Wang, T. and Fehr, W.R. (2004). Quantification of sphingolipid in soybeans. Journal of American Oil Chemists' Society, 81(8), 737-742. https://doi.org/10.1007/s11746-004-0971-y

Huby, E., Napier, J., Baillieu, F., Michaelson, L.V. and Dhondt-Cordelier, S. (2020). Sphingolipids: towards an integrated view of metabolism during the plant stress response. New Phytologist, 225(2), 659-670. https://doi.org/ 10.1111/nph.15997

Ishikawa, T., Ito, W. and Kawai-Yamada, M. (2016). Molecular characterized and targeted quantitative profiling of sphingolipidome in rice. The Plant Journal, 88(4), 681-693. https://doi.org/10.1111/ tpj.13281

Iven, T., Herrfurth, C., Hornung, E., Heilmann, M., Hofvander, P., Stymne, S., Zhu, L.H. and Feussner, I. (2013). Wax ester profiling of seed oil by nanoelectrospray ionization tandem mass spectrometry. Plant Methods, 9(1), 1-14. https:// 
doi.org/10.1186/1746-4811-9-24

Kim, D.S., Kim, S.Y., Chung, J.H., Kim, K.H., Eun, H.C. and Park, K.C. (2002). Delayed ERK activation by ceramide reduces melanin synthesis in human melanocytes. Cellular Signalling, 14(9), 779-785. https://doi.org/10.1016/S0898-6568(02)00024-4

Kim, J. (2008). Wax extraction and characterization from full-fat and defatted rice bran. Louisiana: Louisiana State University, PhD. Dissertation.

Mano, Y., Kawaminnami, K., Kojima, M., Ohnishi, M. and Ito, S. (1999). Comparative composition of color rice lipids (lipid fractions) of indica and japonica rices. Bioscience, Biotechonlogy and Biochemistry, 63(4), 619-626. https://doi.org/10.1271/bbb.63.619

Nilsson, A. (2012). Sphingolipids. Phospholipid Technology and Application, p. 169-194. Sweden: Lund university. https:// doi.org/10.1533/9780857097880.169

Paiva, F.F., Vanier, N.L., Berrios, J.D.J., Pan, J., Villanova, F.A., Takeoka, G. and Elias M.C. (2014). Physiochemical and nutritional properties of pigmented rice subjected to different degree of milling. Journal of Food Composition and Analysis, 35(1), $\quad 10-17 . \quad$ https://doi.org/10.1016/ j.jfca.2014.05.003

Rukmini, K. (1998). Chemical, nutritional and toxicological studies of rice bran oil. Food Chemistry, 30(4), 257-268. https:// doi.org/10.1016/0308-8146(88)90112-4

Saiyot, A., Kaenango, E., Tanaruk, R., Chuenban, T., ASurin, J., Dummi, K., Piyachotisakulchai, N., Jongdee, B., Kotchasatit, A., Kotchasatit, U., Jairin, J., Sattayakul, K., Sudtasarn, G., Wongboon, W., Pemsaen, W., Somjai, T., Mettajit, R., Lhachantuek, S., Promnart, P., Saleetoe, S., Sinsaithai, N., Kaewwisait, N., Jumpagate, R., Sripanom, P., Gaewkumjang, C., Tuntaruk, R., Siripanitcharoen, N., Hormsombut, W., Wongkasem, O., Cobelli, P., Granto, S., Rukchum, P., Kantajun, A., Rattanapun, Y., Sriwilai, K., Chamontri, S., Kunolarn, V., Hompan, P., Buddhaboon, C., Konghakote, P., Suwannavong, A., Pengrat, J., Jongdee, S., Mapakhe, J., Youngsuk, P., Pasopa, S., Srisompan, C., Tansomrot, Y., Kumsanpan, P., Leenat, A., Sakulkoo, E., Changsiri, R., Bureerat, S., Prungkong, T., Akrawong, P., Sunthra, S., Suriyaarunroj, D., Lertna, S., Huntung, P., Kongsuwan, P., Vorawat, O., Boonmee, N., Siddhiwong, N., Yodjai, A., Anseta, J., Srikhum, P., Katesuwan, K., Piboon, K., Yajai, P., Manukul, T., Cheaupan, K., Wongpiyachon, S., Sukviwat, W. Yaosum, K., Lawanprasert, A., Jiarakongmun, S., Sriratanasak, W., Klahkhaeng, K. and Wasusan, A. (2017). Mali
Nil Surin (Mali Dam 2), a non-glutinous rice variety. Thai Rice Research Journal, 8(2), 8-25.

Schmelz, E.M., Sullards, M.C., Dillehay, D.L. and Merrill, A.H. (2000). Colonic cell proliferation and aberaant crypt foci formation and inhibited by dairy glycosphingolipid in 1, 2-dimethylhydrazine-treated CF1 mice. Journal of Nutrition, 130(3), 525-527. https://doi.org/10.1093/jn/130.3.522

Shimoda H. (2009). Natural products supporting the extracellular matrix: rice ceramide and other plant extracts for skin health. In Tabor, A. and Blair, R.M. (Eds). Nutritional Cosmetics: Beauty from Within, p. 319-334. New York: William Andrew Inc. https:// doi.org /10.1016/B978-0-8155-2029-0.50023-5

Sugawara, T. and Miyazawa, T. (1999). Separation and determination of glycolipid from edible plant sources by high-performance liquid chromatography and evaporative light-scatting detection. Lipids, 34(11), 1231-1207. https://doi.org/10.1007/s11745-999-0476 $-3$

Suwanno, S., Sirirat, K., Kaewnango, E., Nookong, B., Plodplong, K., Putsakul, K., Sooksawat, A., Chusiri, L., Klinmanee, C., Tampawisit, S., Cheaupun, K., Wongpiyachon, S., Chotechuen, S., Sriratanasak, W., Wasusun, A. and Taprab, S. (2018). See Bu Guntang 5, a non-glutinouse rice variety. Thai Rice Research journal, 9(1), 5-17.

Takakuwa, N., Saito, K., Ohnishi, M. and Oda, Y. (2005). Determination of glucosylceramide contents in crop tissues and by-products from their processing. Bioresource Technology, 96(9), 10891092. https://doi.org/10.1016/j.biortech.2004.09.019

Vali, S., Ju, Y., Kaimal, T. and Chern Y. (2005). A process for the preparation of food-grade rice bran wax and the determination of the composition. Journal of American Oil Chemists' Society, 82(1), 57 -64. https://doi.org/10.1007/s11746-005-1043-z

Vesper, H., Schmelz, E.M., Nikolova-Karakashian, M.N., Dillehay, D.L., Lynch, D.V. and Merrill, A.H. (1999). Sphingolipids in food and the emerging importance of sphingolipids to nutrition. The Journal of Nutrition, 129, 1239-1250. https:// doi.org/10.1093/jn/129.7.1239

Wongwaiwech, D., Weerawatanakoen, M., Tharatha, S. and Ho, C. (2018). Changpressing methods of rice bran oil processing. Journal of Food and Drug Analysis, 27(1),71-82. https://doi.org/10.1016/ j.jfda.2018.06.006

Yamaguchi, H. and Orgawa, Y. (2012). Analysis of ceramide in soy sauce oil. Journal of American Oil Chemists' Society, 89(11), 2091-2102. https:// doi.org/10.1007/s11746-012-2104-0 
Zhou, Q., Zhang, L., Fu, X.Q. and Chen G.Q. (2002).

Quantification of yeast ceramides using highperformance liquid chromatography-evaporative light-scatting detection. Journal of Chromatography B, 780(1), 161-169. https://doi.org/10.1016/S15700232(02)00466-X 